\title{
A COMPARATIVE STUDY BETWEEN DIRECT TORQUE CONTROL AND PREDICTIVE TORQUE CONTROL FOR AXIAL FLUX PERMANENT MAGNET SYNCHRONOUS MACHINES
}

\author{
Mohsen Siami $^{*}$ - S. Asghar Gholamian ${ }^{* *}$ - Mosayeb Yousefi ${ }^{* * *}$
}

\begin{abstract}
This paper presents a comparative study between direct torque control (DTC) and predictive torque control (PTC) of Axial Flux Permanent magnet Machines (AFPM). In conventional DTC method for permanent magnet machines, only six actives voltage vectors of inverter are used to control torque and flux of machine. But in predictive torque control, in addition to six active voltage vectors, zero voltage vectors are used to control machine. So number of voltage vectors to control AFPM increases that leads to lower ripple of torque and flux. In predictive torque control, the response of torque and flux are computed for all possible switching states of inverter at every sample time according to discrete time model of machine, and then the switching state that optimizes ripple of torque and flux, will be applied in next discrete-time interval. Simulation results which compare the results of implementation of both methods and confirm the good performance of the proposed predictive torque control are presented.
\end{abstract}

K e y w ords: axial flux permanent magnet machine, direct torque control, predictive control, synchronous machine drives, torque ripple

\section{INTRODUCTION}

Permanent magnet (PM) machines due to the advantages such as small size with high efficiency and high reliability, have been receiving much attention. PM machines are divided to tow general groups include of Radial Flux Permanent Magnet (RFPM) machine and Axial Flux Permanent Magnet (AFPM) machine. AFPMs have higher torque to inertia ratio and thus faster dynamic torque response with respect to RFPMs [1].

Two widely used control schemes that are used in commercial are field-oriented control (FOC) and direct torque control (DTC). DTC technique was developed for induction motor drivers [2]. It was applied to permanent magnet drives in 1997 [3]. DTC has faster dynamic torque response with respect to FOC. In DTC, the appropriate inverter configuration is selected from a switching table, according to the signs of the errors between the references of torque and stator flux and their actual values, In order to keep torque and stator flux within a hysteresis band. The main advantage of DTC in comparison with FOC is a faster torque dynamic response. Furthermore DTC is independent of motor parameters except for stator resistance. There are some disadvantages like torque ripple, current distortion and mainly needing the high sampling frequency for digital implementation that are due to the hysteresis based scheme and therefore due to the variable switching frequency. Many studies have been done to solve these problems $[4,5]$.

Predictive control is a control theory that was developed at the end of the 1970s [6]. Variant types of this control strategy have been used for power conversion and motor drive control that mainly associated with modulation techniques [7-11]. The application of this family of nonlinear control techniques for torque and flux control in induction machines (IMs) has received attention from researchers due to the technique's qualities of fast dynamic torque response, low torque ripple, and reduced switching frequency [12-14]. Predictive method was also used to control of PM synchronous machine [15] An alternative technique for controlling the torque and flux of an IM based on state space models has also been investigated [16].

A Predictive direct torque control method has been proposed to overcome drawbacks of DTC for PMSM [17]. In this approach the torque ripple is supposed to be constant. At every sample time, active time (the interval of exerting active voltage vector) and the zero time (the interval of exerting zero voltage vector) are calculated for every 6 active voltage vectors according to discrete time torque model of machine as if that voltage vector is used in the next interval, the torque will not exceed from the band limit. Then the voltage vector that leads to minimum ripple in flux will be applied in next discrete-time interval. So in this method two voltage vectors (active voltage vector and zero voltage vector) and therefore two switching states is applied in every time interval.

But another approach for predictive torque control has been presented for induction machine fed by matrix converter [18]. In this method, torque and flux are evaluated for every valid switching state of the converter based on predictions obtained from a discrete time model of the system. Then the best switching state that minimizes the cost function will be used in next time interval.

\footnotetext{
* Center of Excellence for Power Systems Automation and Operation, Electrical Engineering Department, Iran University of Science and Technology, Tehran 1311416846, Iran, siami@iust.ac.ir ${ }^{* *}$ Faculty of Electrical and Computer Engineering, Babol University of Technology, Babol, Iran, ${ }^{* * *}$ Faculty of Electrical and Computer Engineering Shahid Beheshti University, Evin, Tehran, Iran
} 


\section{CONVENTIONAL DTC}

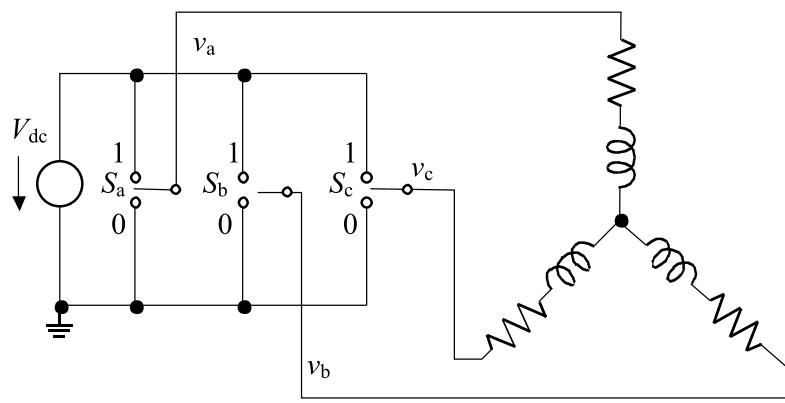

Fig. 1. Simplified representation an inverter-fed AFPM

The objective of this paper is to present a new predictive torque control and to compare the results of implementation of the proposed method and conventional DTC method for a $250 \mathrm{~V}$ and $0.5 \mathrm{HP}$ surface mounted axial flux permanent magnet synchronous machine.

\section{PM MACHIN EQUATIONS}

The equations of the AFPM synchronous machine are same as PMSM. Therefore the machine equations in the rotor reference frame are [19]

$$
\begin{gathered}
v_{d}=R_{s} i_{d}+L_{d} \frac{\mathrm{d} i_{d}}{\mathrm{~d} t}-L_{q} \omega i_{q} \\
v_{q}=R_{s} i_{q}+L_{q} \frac{\mathrm{d} i_{q}}{\mathrm{~d} t}+L_{d} \omega i_{d}+\omega \varphi_{m} \\
T_{e}=\frac{3}{2} p\left[\varphi_{m} i_{q}-\left(L_{q}-L_{d}\right) i_{d} i_{q}\right]
\end{gathered}
$$

where

$v_{d}, v_{q}$ stator voltage on $d$ and $q$ axes;

$i_{d}, i_{q}$ stator current on $d$ and $q$ axes;

$R_{s} \quad$ stator armature resistance, $\Omega$;

$L_{d}, L_{q}$ direct and quadrature inductance, $\mathrm{H}$;

$\omega \quad$ rotor speed in electrical $\mathrm{rad} / \mathrm{s}$;

$T_{e} \quad$ electromagnetic torque, $\mathrm{N} \mathrm{m}$;

$p \quad$ pole pairs;

$\delta \quad$ angle between stator and rotor flux linkage;

$\varphi_{s}, \varphi_{m}$ stator and rotor magnet flux linkage;

For the Surface mounted AFPM (AFPM with uniform air gap) $L_{d}=L_{q}=L_{s}$, and (3) can be simplified as

$$
T=\frac{3 p \varphi_{s} \varphi_{m}}{2 L_{d}} \sin \delta
$$

According to (4) torque can be controlled as fast as possible by keeping the amplitude of the stator flux linkage constant and increasing the rotating speed of the stator flux linkage and so increasing the angel between stator and PM flux. It will be shown in this section that both the amplitude and rotating speed of the stator flux linkage can be controlled by selecting the proper stator voltage vectors [3].

When the stator windings are connected to an inverter as shown in Fig. 1, the voltage vectors in $\alpha-\beta$ plane can defined determined by the status of the three switches, $S_{a}, S_{b}$ and $S_{c}$ so that their respective components are

$$
\begin{gathered}
v_{s}^{(\alpha)}=\frac{V_{d c}}{3}\left[2 S_{a}-S_{b}-S_{c}\right], \\
v_{s}^{(\beta)}=\frac{V_{d c}}{\sqrt{3}}\left(S_{b}-S_{c}\right) .
\end{gathered}
$$

According to the combination of the switching modes, the voltage vectors are specified for eight kinds of vectors. There are six nonzero voltage vectors: $V_{1}(100), V_{1}(110)$, $\ldots$ and two zero voltage vectors: $V_{7}(000)$ and $V_{8}(111)$. The six nonzero voltage vectors are $60^{\circ}$ apart from each other as in Fig. 2, [3].

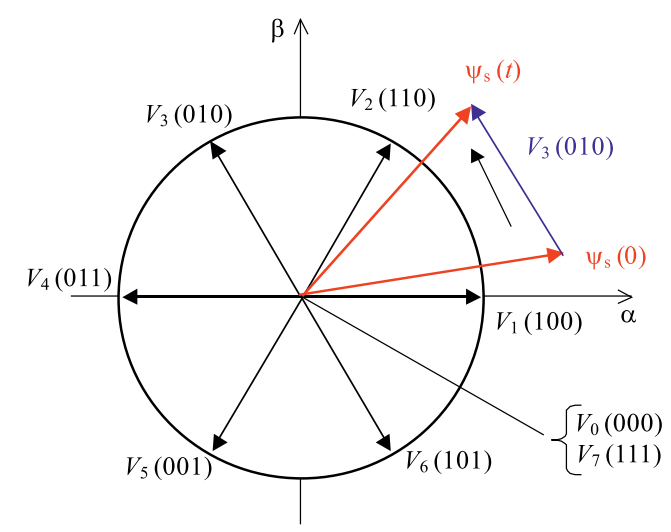

Fig. 2. The movement of stator flux in the space-vector plane

The stator flux linkage of an AFPM in the stationary reference frame can be expressed as

$$
\varphi_{s}=\int\left(v_{s}-R_{s} i_{s}\right) \mathrm{d} t .
$$

During the switching interval, each voltage vector is constant, and (7) is then rewritten as

$$
\phi_{s}=v_{s} t-R_{s} \int i_{s} \mathrm{~d} t+\varphi_{s} \mid t=0 .
$$

According to (8), the trajectory of the stator flux vector will move in the direction of the applied voltage vector if the stator resistance is neglected (Fig. 2). $\varphi_{s} \mid t=0$ is the initial stator flux linkage at the instant of switching. According to Fig. 3, the component voltage vector along 


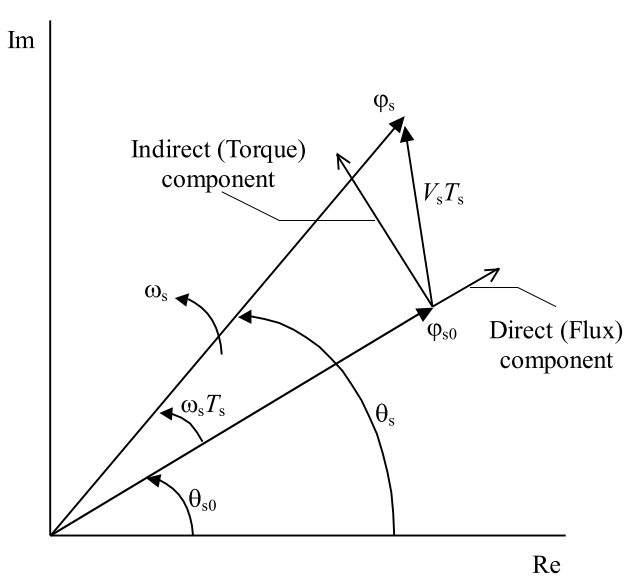

Fig. 3. Effect of components of voltage vector on amplitude and rotational speed of stator flux

Table 1. Switching Table for DTC of AFPM Drive

\begin{tabular}{cccccccc}
\hline \multirow{2}{*}{$\varphi$} & \multirow{6}{*}{$T$} & \multicolumn{6}{c}{$\theta$} \\
\cline { 3 - 8 } & & $\theta(1)$ & $\theta(2)$ & $\theta(3)$ & $\theta(4)$ & $\theta(5)$ & $\theta(6)$ \\
\hline \multirow{2}{*}{$\mathrm{d} \varphi=1$} & $\mathrm{~d} T=1$ & $V_{2}$ & $V_{3}$ & $V_{4}$ & $V_{5}$ & $V_{6}$ & $V_{1}$ \\
& $\mathrm{~d} T=0$ & $V_{6}$ & $V_{1}$ & $V_{2}$ & $V_{3}$ & $V_{4}$ & $V_{5}$ \\
\hline \multirow{2}{*}{$\mathrm{d} \varphi=0$} & $\mathrm{~d} T=1$ & $V_{3}$ & $V_{4}$ & $V_{5}$ & $V_{6}$ & $V_{1}$ & $V_{2}$ \\
& $\mathrm{~d} T=0$ & $V_{5}$ & $V_{6}$ & $V_{1}$ & $V_{2}$ & $V_{3}$ & $V_{4}$ \\
\hline
\end{tabular}

the flux vector alters the amplitude of stator flux and the vertical component alters the rotating speed of stator flux vector.

It is seen from (8) when zero voltage vectors are applied, $\varphi_{s}$ will stay at its original position. This is true for an induction motor since the stator flux linkage is uniquely determined by the stator voltage. In the case of a PM machine, $\varphi_{s}$ will change even when the zero voltage vectors are applied since the magnets rotate with the rotor. Therefore, zero voltage vectors are not used for controlling in AFPM. In other words, $\varphi_{s}$ should always be in motion with respect to the rotor flux linkage.

According to the torque (4), by controlling the amplitude and rotational speed of $\varphi_{s}$, the electromagnetic torque can be controlled effectively. If the actual torque is smaller than the reference, the voltage vectors that keep rotating in the same direction are selected. The angle increases as fast as it can, and the actual torque increases as well. If the actual torque is greater than the reference, the voltage vectors that keep rotating in the reverse direction are selected. The angle decreases, and the torque decreases also. By selecting the voltage vectors in this way, $\varphi_{s}$ is rotated all the time and its rotational direction is determined by the output of the hysteresis controller for the torque.

According to this approach and taking into account the region that flux vector is located, a switching table as shown in Table 1 , can be obtained. In Table $1, \mathrm{~d} \varphi$ and $\mathrm{d} T$ are the outputs of the hysteresis controllers for flux linkage and torque, respectively. $\theta(1)-\theta(6)$ are the region numbers for the stator flux linkage positions. It should be noticed that the flux linkages $\varphi_{\alpha}$ and $\varphi_{\beta}$ at the $k$ th sampling instant are calculated by discrete time model as [3]

$$
\begin{aligned}
& \varphi_{\alpha}(k)=\varphi_{\alpha \mid k-1}+\left(v_{\alpha \mid k-1}-R_{s} i_{\alpha}\right) T_{s}, \\
& \varphi_{\beta}(k)=\varphi_{\beta \mid k-1}+\left(v_{\beta \mid k-1}-R_{s} i_{\beta}\right) T_{s}, \\
& \varphi_{s}(k)=\sqrt{\varphi_{\alpha}^{2}(k)+\varphi_{\beta}^{2}(k)}
\end{aligned}
$$

and torque calculated as

$$
T=\frac{3}{2} p\left[\varphi_{\alpha}(k) i_{\beta}(k)-\varphi_{\beta}(k) i_{\alpha}(k)\right]
$$

where $T_{s}$ is the sampling interval and the variables with subscript $k-1$ are the previous samples. As seen this equations are independent of motor parameters except for stator resistance. But The initial values of $\varphi_{\alpha}$ and $\varphi_{\beta}$ are not zero for PM machines. These can be obtained from an encoder. But if the initial values of $\varphi_{\alpha}$ and $\varphi_{\beta}$ can be estimated, the encoder may entirely be eliminated. For example we can use an external magnet to locate the rotor in a special position so we can estimate the initial values of $\varphi_{\alpha}$ and $\varphi_{\beta}$.

\section{PROPSED PREDICTIVE TORQUE CONTROL}

Predictive torque control (PTC) consists of choosing one of the 8 feasible switching states of the inverter, at fixed sampling intervals. The strategy to select the switching state for the every time interval is based on minimization of quality function. The quality function $Q F$ represents the evaluation criteria in order to select the best switching state for the next sampling interval. For the computation of $Q F$, by means of a mathematical model of the AFPM the electric torque $T_{e}$, and the stator flux $\varphi_{s}$ on the next sampling interval are predicted, for each valid switching state. These predicted values are indicated by the superscript " $p$ " and are compared with their reference values denoted by the superscript "** within $Q F$. A proportional-integral (PI) controller is used to generate the reference torque $T_{e}^{*}$ for the predictive algorithm.

\subsection{Quality Function $Q F$}

The quality function represents the evaluation criteria used to decide which switching state is the best to apply. The function is composed of the absolute error of the predicted torque, the absolute error of the predicted flux magnitude, resulting in

$$
Q F=\lambda_{T}\left|T_{e}^{*}-T_{e}^{p}\right|+\lambda_{\text {varphi }}|| \varphi_{s}^{*}|-| \varphi_{s}^{p}||
$$


where $\lambda_{T}$ and $\lambda_{\text {varphi }}$ are weighting factors that handle the relationship between torque and flux conditions. To maintain $Q S$ as a magnitude without a physic interpretation, $\lambda_{T}$ is measured in $\mathrm{N} / \mathrm{m}$ and $\lambda_{\text {varphi }}$ in weber inverse. The quality function must be calculated for each of the 8 feasible switching states. The state that generates the optimum value, in this case a minimum, will be chosen and applied during the next time interval. The state that generate the higher predictions of torque error and flux error will be penalized with higher values of $Q F$, and thus, will not be selected. In this sense, the technique assigns costs to the objectives reflected in $g$, weighted by $\lambda_{T}$ and $\lambda_{v a r p h i}$ and then chooses the switching state that presents the lowest cost.

\subsection{Models Used to Obtain Prediction}

In this section, a mathematical discrete-time model is derived to predict the behavior of the system under a given switching state, based on the well-known equations of the surface-mounted PM synchronous machine. The voltage equations in a $d-q$ system of coordinates are expressed as (1) and (2). The electromagnetic torque developed by the AFPM can be expressed as follows

$$
T_{e}=\frac{3}{2} p\left[\varphi_{m} i_{q}-\left(L_{q}-L_{d}\right) i_{d} i_{q}\right]
$$

For simplicity a surface mounted AFPM is considered $\left(L_{q}=L_{d}=L_{s}\right)$. The electromagnetic torque expressed in (14) is simplified to

$$
T_{e}=\frac{3}{2} p \varphi_{m} i_{q}
$$

The derivative of the electromagnetic torque is

$$
\frac{\mathrm{d} T_{e}}{\mathrm{~d} t}=\frac{3}{2} p \varphi_{m} \frac{\mathrm{d} i_{q}}{\mathrm{~d} t}
$$

Resolving for the derivative of $i_{q}$ in (2)

$$
\frac{\mathrm{d} i_{q}}{\mathrm{~d} t}=\frac{1}{L_{q}}\left[v_{q}-R_{s} i_{q}-L_{d} \omega i_{d}-\omega \varphi_{m}\right] .
$$

In order to predict the current and torque values for the next sampling instant $t(k+1)$, a discrete-time set of equations can be derived from the continuous-time model. For small values of the control sampling time $T_{s}$, the quadrature axis current $i_{q}$ at $t(k+1)$ can be calculated as follows

$$
i_{q}(k+1)=i_{q}(k)+\frac{\mathrm{d}}{\mathrm{d} t} i_{q}(k) T_{s}
$$

Substituting in (16) yields

$$
\begin{aligned}
& i_{q}(k+1)=i_{q}(k)+ \\
& \quad \frac{T_{s}}{L_{q}}\left[v_{q}(k)-R_{s} i_{q}(k)-L_{d} \omega(k) i_{d}(k)-\omega(k) \varphi_{m}\right] .
\end{aligned}
$$

Substituting (19) in (15), the electromagnetic torque at instant $t(k+1)$ is obtained as follows [20]

$$
\begin{aligned}
& T_{e}(k+1)=\frac{3}{2} p \varphi_{m}\left\{i_{q}(k)+\right. \\
& \left.\quad \frac{T_{s}}{L_{q}}\left[v_{q}(k)-R_{s} i_{q}(k)-L_{d} \omega(k) i_{d}(k)-\omega(k) \varphi_{m}\right]\right\}
\end{aligned}
$$

For prediction of stator flux, we should calculate stator flux components in $\alpha-\beta$ system of coordinates. Since the calculations are realized in an $\alpha-\beta$ stator frame of coordinates, (1) and (2) are transformed into $\alpha-\beta$ coordinates. The flux in each stator fixed axis can be split into one term depending on the rotor position and the PM flux and a second originated by the current in the corresponding axis as follow

$$
\begin{array}{ll}
\varphi_{s \alpha}=R_{s} i_{s \alpha}+\varphi_{m \alpha}, & \varphi_{m \alpha}=\varphi_{m} \cos (\theta), \\
\varphi_{s \beta}=R_{s} i_{s \beta}+\varphi_{m \beta}, & \varphi_{m \beta}=\varphi_{m} \cos (\theta) .
\end{array}
$$

Thus, the voltage equations result in

$$
\begin{aligned}
& v_{\alpha}=R_{s} i_{s \alpha}+L_{s} \frac{\mathrm{d} i_{\alpha}}{\mathrm{d} t}-\omega \varphi_{m} \sin (\theta), \\
& v_{\beta}=R_{s} i_{s \beta}+L_{s} \frac{\mathrm{d} i_{\beta}}{\mathrm{d} t}+\omega \varphi_{m} \sin (\theta) .
\end{aligned}
$$

According to (8), the components of stator flux in $\alpha-\beta$ stator frame at instant $t(k+1)$ are

$$
\begin{aligned}
& \varphi_{s \alpha}(k+1)=\varphi_{s \alpha}(k)+v_{\alpha}(k) T_{s}-R_{s} \int i_{\alpha} \mathrm{d} t \\
& \varphi_{s \beta}(k+1)=\varphi_{s \beta}(k)+v_{\beta}(k) T_{s}-R_{s} \int i_{\beta} \mathrm{d} t .
\end{aligned}
$$

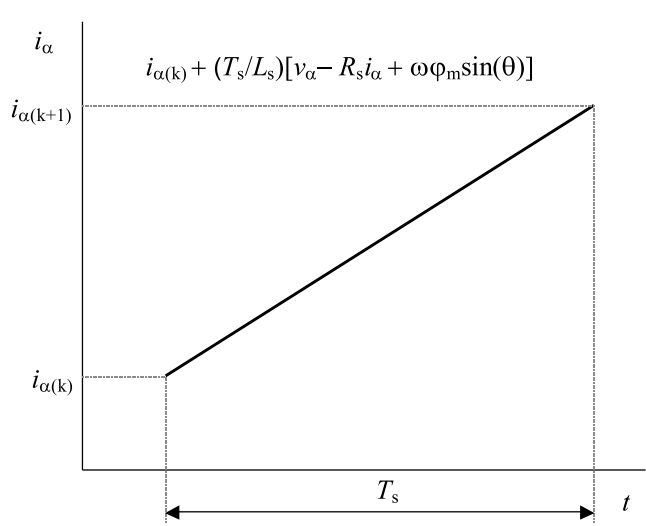

Fig. 4. Current $i_{\alpha}$ during a switching interval 


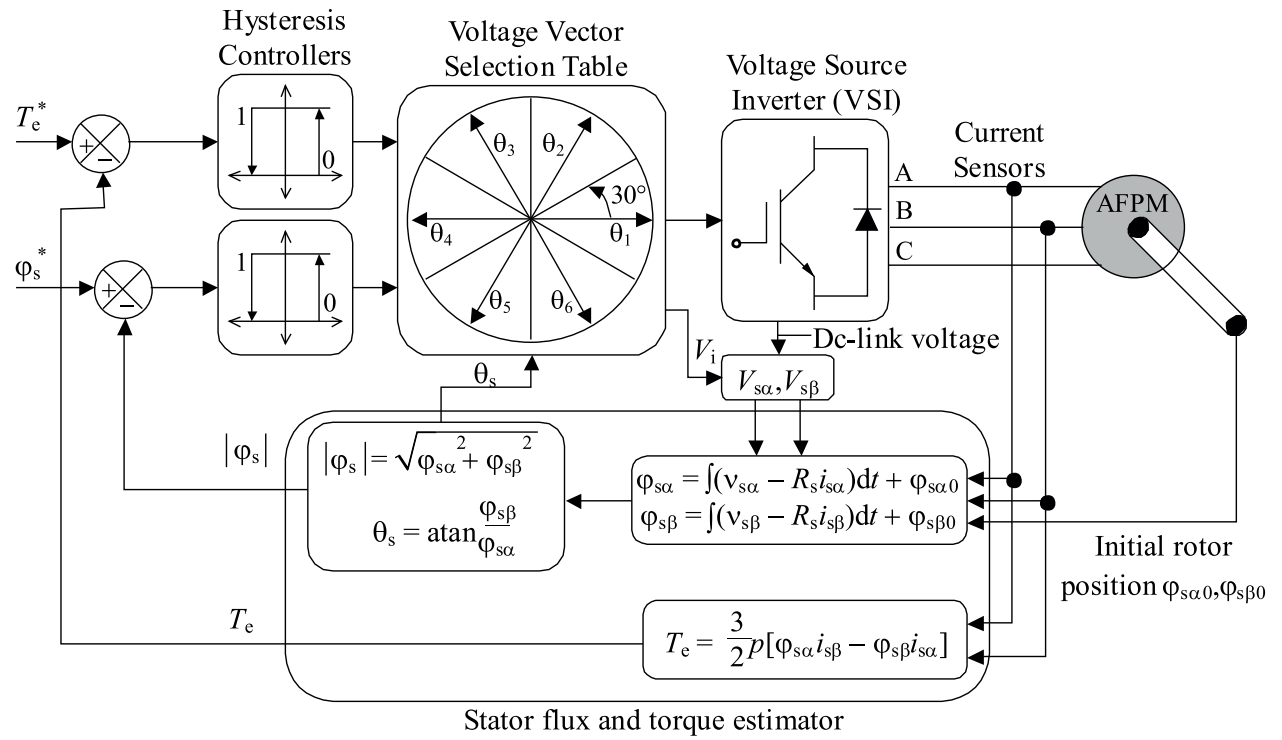

Fig. 5. Block diagram for DTC of AFPM drive

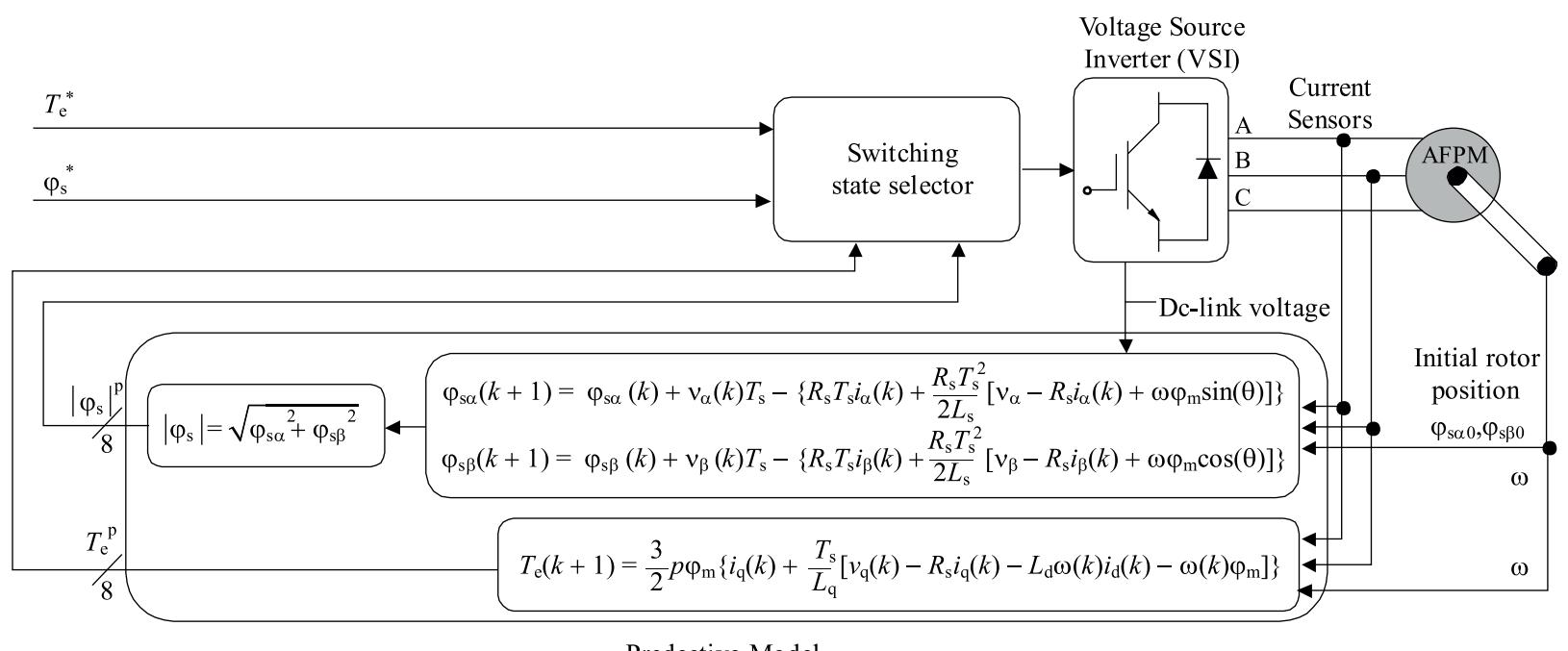

Predective Model

Fig. 6. Block diagram for proposed Predictive Torque Control of AFPM drive

Table 2. AFPM Parameters in Simulation Model

\begin{tabular}{ccc}
\hline Parameter & Description & Value \\
\hline$p$ & number of pole pairs & 4 \\
$R(\Omega)$ & stator resistance & 0.2 \\
$L_{d}, L_{q}(\mathrm{mH})$ & stator inductance & 8.5 \\
$\varphi_{m}(\mathrm{~Wb})$ & rotor magnet flux & 0.175 \\
$j\left(\mathrm{~kg} \mathrm{~m}^{2}\right)$ & rotor inertia & 0.089 \\
$B$ & damping coefficient & 0.005 \\
$V_{D C}(\mathrm{~V})$ & DC voltage & 250 \\
$\omega_{r}(\mathrm{rpm})$ & rated speed & 300 \\
$T_{N}(\mathrm{~N} \mathrm{~m})$ & rated torque & 11 \\
- & power switches & IGBT \\
\hline
\end{tabular}

The current within a switching interval has the trajectory shown in Fig. 4 . So $i_{\alpha}$ and $i_{\beta}$ during time interval $[t(k), t(k+1)]$ are

$$
\begin{aligned}
& i_{\alpha}(t)=i_{\alpha}(k)+\frac{\mathrm{d} i_{\alpha}}{\mathrm{d} t} t, \\
& i_{\beta}(t)=i_{\beta}(k)+\frac{\mathrm{d} i_{\beta}}{\mathrm{d} t} t .
\end{aligned}
$$

Resolving for the derivative of $i_{\alpha}$ and $i_{\beta}$ in (27) and (28),

$$
\begin{aligned}
\frac{\mathrm{d} i_{\alpha}}{\mathrm{d} t} & =\frac{1}{L_{s}}\left[v_{\alpha}-R_{s} i_{\alpha}+\omega \varphi_{m} \sin (\theta)\right], \\
\frac{\mathrm{d} i_{\beta}}{\mathrm{d} t} & =\frac{1}{L_{s}}\left[v_{\beta}-R_{s} i_{\beta}-\omega \varphi_{m} \cos (\theta)\right],
\end{aligned}
$$

Thus according to (25)-(30),

$$
\begin{aligned}
\varphi_{s \alpha}(k+1)= & \varphi_{s \alpha}(k)+v_{\alpha}(k) T_{s}-\left\{R_{s} T_{s} i_{\alpha}(k)+\right. \\
& \left.\frac{R_{s} T_{s}^{2}}{2 L_{s}}\left[v_{\alpha}-R_{s} i_{\alpha}(k)+\omega \varphi_{m} \sin (\theta)\right]\right\},
\end{aligned}
$$




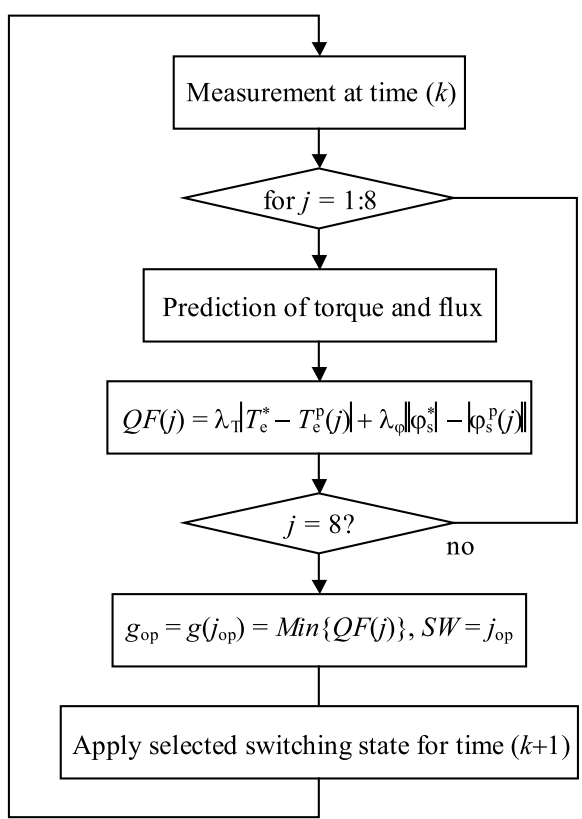

Fig. 7. Flowchart of the proposed predictive control

$$
\begin{aligned}
\varphi_{s \beta}(k+1)= & \varphi_{s \beta}(k)+v_{\beta}(k) T_{s}-\left\{R_{s} T_{s} i_{\beta}(k)+\right. \\
& \left.\frac{R_{s} T_{s}^{2}}{2 L_{s}}\left[v_{\beta}-R_{s} i_{\beta}(k)+\omega \varphi_{m} \cos (\theta)\right]\right\} .
\end{aligned}
$$

Equations (20), (31) and (32) are used to obtain predictions of torque and flux for each of the 8 valid switching combinations. Then the switching state that minimizes (13), will be applied in next time interval.

It should be noticed that the change of the reference flux amplitude between no-load and rated torque conditions is not large; nevertheless, its correction according to the actual torque enhances the overall efficiency of the system. Thus the amplitude of the stator flux results from the constant value of the PM flux as

$$
\left|\phi_{s}^{*}\right|=\sqrt{\varphi_{m}^{2}+\left(\frac{2}{3} \frac{T_{e}^{*} L_{s}}{p \varphi_{m}}\right)^{2}} .
$$

\section{SIMULATION RESULTS}

A SIMULINK model was used in order to verify the behavior of the proposed predictive torque control and compare it with conventional DTC that are presented in this paper. Simulation parameters (such as AFPM and voltage source inverter) are listed in Table 2.

\subsection{Simulation of a AFPM Drive with DTC}

The block diagram of the conventional DTC is shown in Fig. 5. As shown in this figure the torque and flux motor are calculated by means of machine equations in stationary reference frame. Then magnitudes of torque and flux are compared to their reference values in hysteresis controllers. According to hysteresis controllers and the region that stator flux is located, the voltage vector and thus the switches state will be selected from the switching table.

In modeling, it is assumed the band widths of torque and flux hysteresis controllers are $0.01 T_{e}^{*}$ and $0.01 \varphi_{s}^{*}$ respectively. And also, it is assumed that the rotor starts at its initial position $\theta=0$, so the initial region of flux is $\theta(1)$. The reference torque changes abruptly from 11 to $-11 \mathrm{Nm}$ at $t=0.175 \mathrm{~s}$ and from -11 to $11 \mathrm{Nm}$ at $t=0.175 \mathrm{~s}$.

According to (8) and Fig. 3, it is clear that voltage magnitude of DC link and also sample time, have important effect on torque and flux changes and smaller sample time leads to smaller ripples of torque and flux. In this paper $T_{s}=10 \mu \mathrm{s}$ is assumed for simulation.

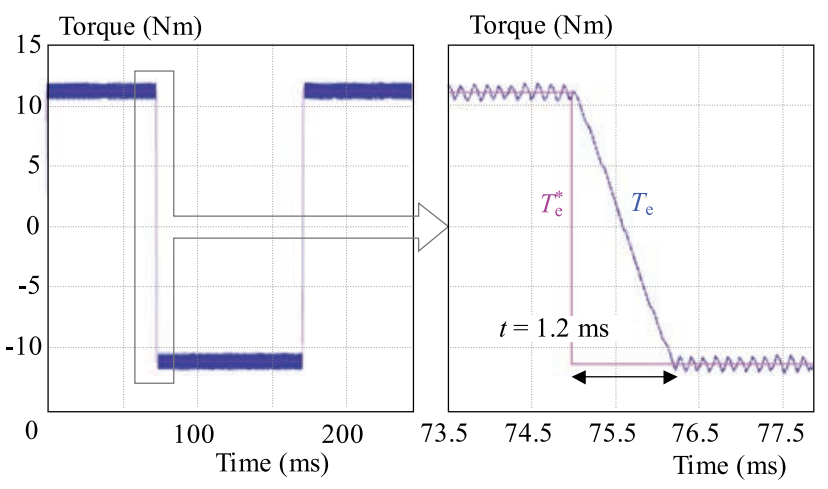

(a)

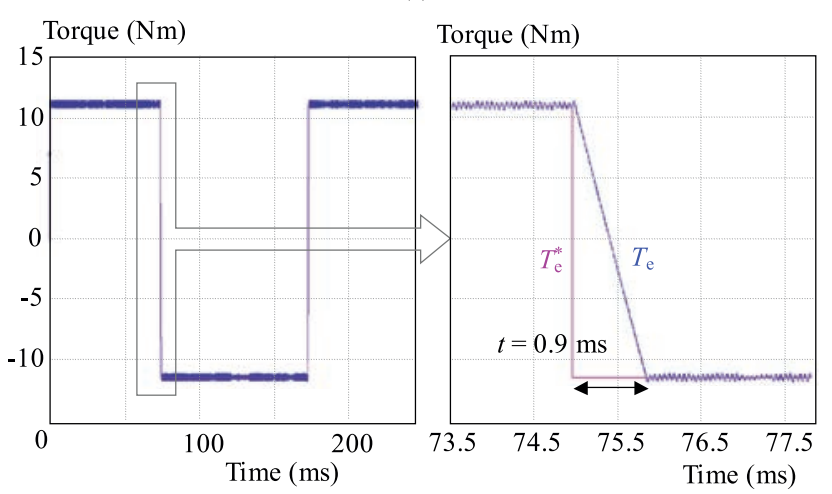

(b)

Fig. 8. Torque response of AFPM: (a) - conventional DTC, (b) - predictive torque control

The torque response is shown on Fig. 8a. As this figure shows, the actual torque follows reference torque very fast when reference torque changes. In steady state when reference torque is constant, actual torque is controlled within the bandwidth. Figure 9a. shows stator flux that is controlled within the bandwidth too. The trajectory of $\varphi_{\alpha}$ and $\varphi_{\beta}$ is a circle as expected that is shown on Fig. 10a. 
$\varphi_{\mathrm{s}}(\mathrm{Wb})$
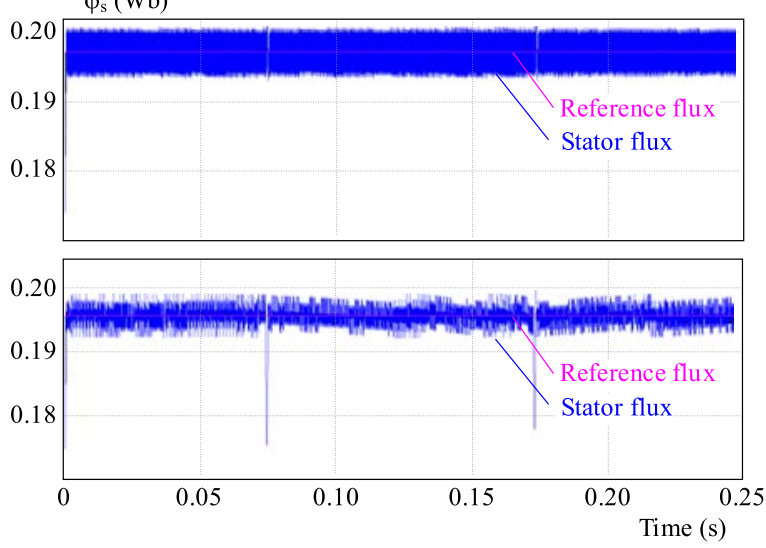

Fig. 9. Stator flux: (a) - conventional DTC, (b) - predictive torque control

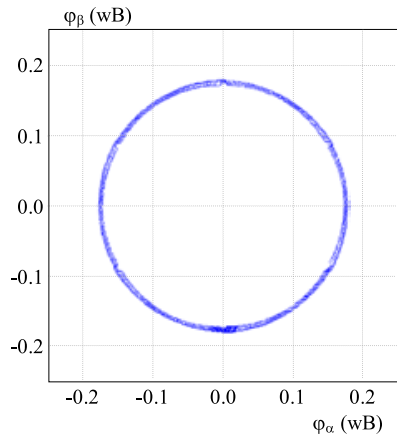

(a)

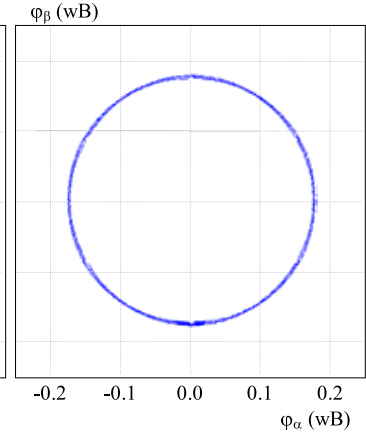

(b)
Fig. 10. Torque response of AFPM: (a) - conventional DTC, (b) - predictive torque control

\subsection{Simulation of a AFPM Drive with proposed Predictive Torque Control}

The block diagram of the proposed predictive torque control is shown in Fig. 6. As shown in this figure, unlike DTC this control method does not need switching table, and the proper switching state in each time interval is selected according to flowchart that is shown in Fig. 7. To calculate torque and flux for each possible switching state the discrete time model of machine is used that has been presented in this paper.

The motor torque with this control method is shown in Fig. 8b. As it is observed, in comparison with motor torque in DTC method that is shown in Fig. 8a, torque ripple is reduced in predictive torque control. Furthermore, dynamic torque response is improved too, when reference torque changes.

Stator flux is shown in Fig. 9b, and as it shows, the flux ripple is reduced too, in comparison with DTC. The trajectory of $\varphi_{\alpha}$ and $\varphi_{\beta}$ is a circle with less ripple as expected that is shown on Fig. 10b.

Stator currents for both DTC and predictive torque control have been shown on Fig. 11. As observed the ripple current for predictive control is less than DTC that leads to less harmonics and losses in stator coil.
However, drawback of predictive torque control with regard to DTC is that the DTC controllers as shown on Fig. 5 and (9)-(12) are independent of motor parameters except for the stator resistance, which affects only the low-speed performance of the drive and can be compensated. The inductances and back EMF constant, which change with the saturation and temperature, respectively, are not used in the controller, and, therefore, there is no need to be compensated for the saturation and back EMF constant variation. But since predictive torque control uses machine mathematical model that is estimation of actual model in ideal state and dependents on all machine parameters, so changes of The inductances and back EMF constant due to saturation and temperature, can disturb control process. Furthermore, unlike DTC method, predictive torque control needs rotor speed. So the drive needs a speed sensor that increases volume and cost of drive.

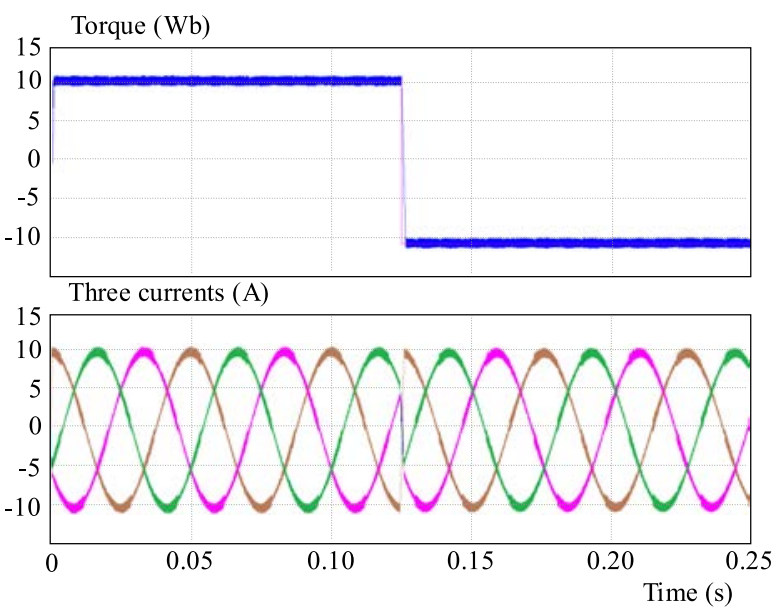

(a)

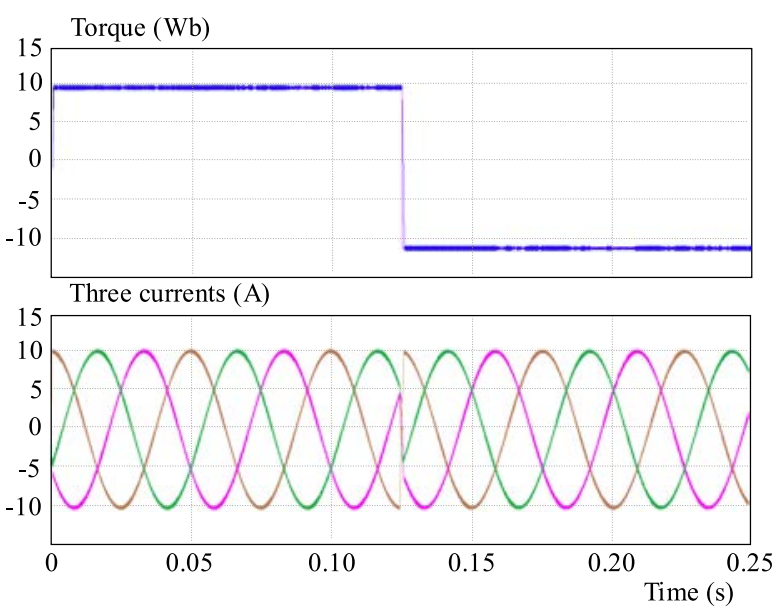

(b)

Fig. 11. Three phase stator currents of AFPM: (a) - conventional DTC, (b) — predictive torque control

\section{CONCLUSION}

Two control methods for Permanent Magnet Synchronous Motor include of Direct Torque Control and 
Predictive Torque Control have been explored in this article. The mathematical equations for implementation of each method have been presented. It have been shown that the proposed predictive torque control opposite to conventional DTC, in addition active voltage vectors, uses zero vectors to control motor. The simulation results show that proposed predictive torque control has faster dynamic response with regard to conventional DTC. Furthermore, in steady state it has less ripple of torque, flux, and stator currents that leads to less losses and so more efficiency and more lifetime of machine. However, since DTC method is independent of machine parameters except for stator resistance, although the inductances and back EMF constant which change with the saturation and temperature, respectively, there is no need to be compensated for the saturation and back EMF constant variation. Furthermore, DTC in contrast with predictive torque control, dose not need a sensor speed that leads to increase of reliability of system and also reduction of cost and volume of the derive.

\section{REFERENCES}

[1] RAHIM, N. A.-HEW, W. P.-MAHMOUdI, A.: Axial-Flux Permanent-Magnet Brushless DC Traction Motor for Direct Drive of Electric Vehicle, International Review of Electrical Engineering 6 No. 2 (2011).

[2] TAKAHASHI, I.-NOGUCHI, I. A New Quick-Response and High-Efficiency Control Strategy of an Induction Motor : IEEE Trans. Ind. Appl. 22 No. 5 (1986), 820-827.

[3] ZHONG, L.-RAHMAN, M. F.-HU, W. Y.-LIM, K. W.: Analysis of Direct Torque Control in Permanent Magnet Synchronous Motor Drives, IEEE Trans. Power Electronics 12 (May 1997), 528-536.

[4] BUJA, G. S.-KAZMIERKOWSKI, M. P. : Direct Torque Control of PWM Inverter-Fed AC Motors - a Survey, IEEE Trans. Ind. Electron. 51 No. 4 (2004), 744-757.

[5] TANG, L.-ZHONG, L.-RAHMAN, M. F.-HU, Y.: A Novel Direct Torque Controlled Interior Permanent Magnet Synchronous Machine Drive with Low Ripple in Flux and Torque and Fixed Switching Frequency, IEEE Trans. Power Electron. 19 No. 2 (2004), 346-354.

[6] CAMACHO, E.-BORDOnS, C.: Model Predictive Control, Springer-Verlag, Berlin, Germany, 1999.

[7] KENNEL, R.-LINDER, A.: Predictive Control of Inverter Supplied Electrical Drives, in Proc. Conf. Rec. IEEE (Power Electron. Spec. Conf.), vol. 2, 2000, pp. 761-766.

[8] MOON, H.-T.-KIM, H.-S.-YOUN, M.-J. : A Discrete-Time Predictive Current Control for PMSM, IEEE Trans. Power Electron. 18 No. 1 (Jan 2003), 464-472.

[9] Wipasuramonton, P.-ZHU, Z. Q.-HOWE, V: Predictive Current Control with Current-Error Correction for PM Brushless AC Drives, IEEE Trans. Ind. Appl. 42 No. 4 (Jul/Aug 2006), 1071-1079.

[10] BÉLAI, I.-ŽALMAN, M. : Predictive Current Controller of the Vector-Controlled of Asynchronous Motor, Journal of Electrical Engineering 48 No. 7-0 (1997), 201-204.

[11] GeYeR, T.-PAPAFOtioU, G.-MORARI, M. : Model Predictive Direct Torque Control, Part I: Concept, Algorithm and Analysis, IEEE Trans. Ind. Electron. 56 No. 6 (Jun 2009), 1894-1905.

[12] CORREA, P.-PACAS, M.-RODRÍGUEZ, J. : Predictive Torque Control for Inverter-Fed Induction Machines, IEEE Trans. Ind. Electron. 54 No. 2 (Apr 2007), 1073-1079.
[13] DROBNiC, K.-NEMEC, M.-NEDELJKOVIC, D.-AMBROZIC, V.: Predictive Direct Control Applied to AC Drives and Active Power Filter, IEEE Trans. Power Electron. 56 No. 6 (Jun 2009), 1884-1892.

14] NEMEC, M.-NEDELJKOVIC, D.-AMBROZIC, V.: Predictive Torque Control of Induction Machines using Immediate Flux Control, IEEE Trans. Ind. Electron. 54 No. 4 (Aug 2007), 2009-2017.

15] SiAmi, M.-GHOlamian, S. A. : Predictive Torque Control of Three Phase Axial Flux Permanent Magnet Synchronous Machines, Majlesi Journal of Electrical Engineering 6 No. 2 (2012), $7-143$.

16] MIRANDA, H.-CORTÉS, P.-YUZ, J. I.-RODRÍGUEZ, J. : Predictive Torque Control of Induction Machines based on State Space Models, IEEE Trans. Ind. Electron. 56 No. 6 (Jun 2009), 1916-1924.

17] PACAS, M.-WEBER, J.: Predictive Direct Torque Control for the PM Synchronous Machine, IEEE Trans. Ind. Electron. 52 No. 5 (Oct 2005), 1350-1356.

18] VARGAS, R.-RODRÍGUEZ, J.-AMMANN, U.-WHEELER, P.: Predictive Torque Control of an Induction Machine Fed by a Matrix Converter with Reactive Power Control, IEEE Trans. Power Electron 25 No. 6 (Jun 2010), 1426-1438.

[19] TANG, L.-ZHONG, L.-RAHMAN, M. F.-HU, Y.: A Novel Direct Torque Control for Interior Permanent-Magnet Synchronous Machine Drive with Low Ripple in Torque and Flux - A Speed-Sensorless Approach, IEEE Trans. Ind. Application. 39 No. 6 (Nov 2003), 1748-1756.

20] ORTEGA, C.-ARIAS, A.-ESPINA, J.: Predictive Direct Torque Control of Matrix Converter fed Permanent Magnet Synchronous Machines, in Proc. Conf. Rec. IEEE (Ind. Electron ISIE., Nov 2010, pp. 1451-1455.

21] KARNAVAS, Y. L.-PAPADOPOULOS, D. P.: Excitation Control of a Synchronous Machine using Polynomial Neural Network, Journal of Electrical Engineering 55 No. 7-8 (2004), 169-179.

Received 14 February 2012

Mohsen Siami was born in Behshahr, Iran, in 1986. He received his BSc degree in electrical engineering from University of Guilan, Rasht, Iran in 2009 and his MSc degree in electrical engineering from Babol University of Technology, Babol, Iran, in 2012. He is presently pursuing his PhD at Iran University of Science and Technology (IUST) in Tehran. Since 2013 he is a lecturer at IUST. His research interests include electrical machines drive, power electronic and optimization problems.

S. Asghare Gholamian was born in Babolsar, Iran, in 1976. He received a BSc, degree in electrical engineering from K.N. Toosi University of Technology, Tehran, Iran in 1999 and a MSc degree in electric power engineering (electrical machine) from university of Mazandaran, Babol, Iran in 2001. He also received the PhD degree in electrical engineering from K. N. Toosi University of Technology, Tehran, Iran in 2008. He is currently an assistant professor in department of Electrical engineering at the Babol University of Technology, Iran. His research interests include power electronic design , simulation, modeling and control of electrical machines (motor, generator and transformer).

Mosayeb Yousefi was born in Nour, IRAN, in 1986. He received his BSc degree in electrical engineering from University of Guilan, Rasht, IRAN in 2009 and his MSc degree in electrical engineering at Shahid Beheshti University, Evin, Tehran, Iran. His research interests include motor control and power electronics. 